\title{
A Systematic Review of Tech-supported Collaborative Creativity Practices in the Field of Education
}

\author{
Burcu Gündoğdu*a, Ali Merç ${ }^{\mathrm{b}}$ \\ a(ORCID ID: 0000-0002-0073-8369), İstanbul Kültür University, İstanbul, Turkey, b.gundogdu@iku.edu.tr \\ b(ORCID ID: 0000-0003-3061-7899), Anadolu University, Eskişehir, Turkey, amerc@ anadolu.edu.tr \\ *Corresponding author
}

\section{ARTICLE INFO}

Received: 17 July 2021

Revised: 14 October 2021

Accepted: 4 November 2021

Keywords:

Collaborative creativity Technology-

enhanced practices

Teacher and students' roles

Problems

Solutions

doi: $10.53850 /$ joltida. 953760

\begin{abstract}
This study aims to make a systematic review of technology-supported collaborative creativity pedagogy and practices in the field of education by focusing on peer-reviewed articles published in journals between 2014 and 2019. The targeted educational levels were specified as elementary, secondary education and teacher education students. 21 studies were examined from different aspects: (a) forms of technology and technological features with pedagogical affordances and (c) teachers and students' roles, and the pedagogical approach, (c) problems and solutions. A narrative synthetic approach was employed to categorize, analyse and synthesize the data according to themes developed. The findings indicate majority of the studies employed different types of pedagogies, and yet all follow student-directed pedagogies or theories drawing on social-constructivism. In the selected studies, three teachers' roles were identified: giving planned or explicit guidance, promoting dialogue between students during the process of creation and orchestrating collaborative creativity flow of students. And, students' roles were also found to be in parallel with the teachers' roles. With regard to forms of technology, among 5 major technological forms, web-based were the favoured technology due to its affordances. Besides, the selected studies showed there are teacher-related, student-related and techrelated problems, and students overcome these problems through solving the problem together, being considerate about their team members and valuing their teachers' effort. Therefore, the papers selected for this review indicated that the problems were not perceived as obstacles to collaborative creativity both by students and teachers. Instead, they were considered as a means to boost collaboration and creativity.
\end{abstract}

\section{INTRODUCTION}

Today, there has been an increasing attention to enhancement of skills of collaboration and creativity in different subject domains as a part of 21st learning agenda. Thanks to technology, many things can be accomplished in a collaborative way by working together as a team. In educational context, technology has impelled both teachers and students to act outside their traditional comfort zone, and this has changed their ways of teaching and learning a subject.

$21^{\text {st }}$ century has now been demanding creation through collaboration by using technology in educational contexts. In the related literature, it is argued that ICT can promote creative thinking by means of its contribution to problem solving, creative knowledge and social interaction. And through this social interaction, it is believed that ICT enables users to create content with others collaboratively, and promote interaction and communication with students. (Wheeler, Waite, \& Bromfield, 2002)

In the last couple of decades, the definition of creativity has altered. Creativity, which was defined as individual process, has been tackled differently than before, affected by social constructivism (Vygotsky, 1987). Consequently, a new strand of theory called "collaborative creativity" has emerged, which emphasizes collaboration and dialogue in creation process of a product that manifests both novelty and social value (Sawyer, 2013; Glăveanu, 2014). Collaboration is now believed to be at the heart of creative practice and due to its multi-layered nature with diverse levels and characteristics, doing collaborative work has its own benefits as and challenges for creative production. To accomplish collaboration, some elements are vital, and if they are involved, then it is certain that the benefits will be more. Supporting this view, Sonnerburg (2004) proposed a collaborative creative framework that highlights the importance of communication and togetherness for creating in collaboration, and defines some characteristics accordingly such as being open to communication, trusting each other and being ready to take risks.

In this vein, collaboration is not easy to put into practice. It requires harmony out of dissonance, and it is not easy to embrace and expand the spirit of positive relations of interdependence when everybody has its own reality and way of doing things. In the study of Chiu and Hsiao's (2010), 290 middle school students' responses to the interview questions showed that there are four different types of interaction occur among students: passive, silent, off- task behaviour and active knowledge-sharing. This study shows students should share what they know with each other, and the other types of interaction should occur less frequently if creative collaboration is desired to be accomplished. Besides, Eteläpelto and Lahti (2008) discussed another challenge for collaboration in their study. They argued some students are emotionally sensitive in-group works, and as a solution to this, they explained teachers' 
demanding responsibility: a teacher should provide emotional scaffolding, encourage students to give supportive comments to each other, and set groups based on history of shared working, thus ensuring students to feel comfortable while working together. This is one standpoint given in one study regarding teachers' role. But in fact, there are varying views for teachers' role to promote collaborative creativity among students.

Regarding teachers' role, there are two opposing views: some believe that teachers should adopt deep learning approach and they should act as moderators, not as instructors (i.e., should advise and facilitate learning, but should avoid direct or explicit instruction) (Beijaard, Verloop, \& Vermunt, 2000; Huang, 2002). On the other hand, some other scholars highlight the importance of use of strategies by students, guidance of students towards desired attitude, and use of explicit directions by teacher (Kirschner, Sweller \& Clark, 2006; Daemmrich, 2010; Lin \& Yang, 2011). Aside from being equipped with sufficient competence in using technology, teachers re expected to manage the balance between control and flexibility in their pedagogical design and teaching. They also need to consider the challenges and affordances of task (ie. matching technology and task), technological literacy level of students as well as the needs of students, and these all render teachers' role even more sensitive and demanding. In this sense, there are so many variables that teachers need to be in control of.

As long as there is an appropriate use of pedagogical approach as well as pedagogically appropriate use of technology, technology is considered to enable collaborative creativity nurturing platform with wide range of tools (Henriksen, Mishra, and Fisser, 2016). Therefore, one of the persisting agenda of today has become designing technology-enhanced pedagogy for promoting collaborative creativity skills in different subject domains (Craft, 2012). In the literature, this issue has not yet been systematically reviewed in terms of classroom pedagogy and practices conducted at various settings and disciplines. However, it is known that teachers need a synthesis of contemporary, evidenced based practices that foster collaborative creativity of students by technology use. Therefore, this review aimed to fill this research gap and findings from this study are supposed to build practice that is more effective in the future by identifying conditions and resources for co-creativity. To that end, three guiding research questions were formed in order to reach an understanding for the conditions that is supportive of collaborative creativity.

RQ1: In the selected studies, what forms of technology have been preferred to support collaborative creativity practices among students? And what are the pedagogical affordances these technologies?

RQ2: What are the common pedagogical approaches and the most preferred roles of teacher(s) and student(s) in order to foster collaborative creativity?

RQ3: What problems and possible solutions regarding collaborative creativity practices have been discussed in the selected studies?

To be able to answer proposed research questions above, 21 studies were examined from different aspects: research focus, forms of technology and technology with pedagogical affordances, teachers and students' roles, pedagogical approaches. And based on these analyses, key findings and implications are also discussed comprehensively. And as a result, this study presents some important steps that need to be followed by an instructor to foster collaborative creativity with a figure including steps to guide future studies for implementation.

\section{METHODOLOGY}

\section{Literature Search and Criteria for Paper Selection}

The present study covered studies that have focused on tech-supported collaborative creative practices of a five-year time frame 2014-2019, with a view to portraying the recent practices across the field of education. The collaborative creativity, which is the subject-matter of this study, appeared in a few studies in 2008, but it was seen to appear more commonly in studies after 2010, a date marked by the release of iPad and android tablets. However, in this study, the five-year time frame between 2014 and 2019 was chosen to be examined because as indicated by Johnson, Adams, Becker, Estrada, \& Freeman (2014) in in NMC Horizon Report published in 2014, there is an increasing presence of technology in schools as an opportunity to foster collaboration and creativity as a primary goal, not as a sub-goal to improve the performance of another skill.

Following the methodological framework proposed by Levac, Colquhoun, and O'Brien. (2010), the paper selection was carried out in five phases: a) identifying the corresponding research questions, b) identifying studies that are relevant for those questions, c) selecting studies, d) charting data, and e) summarizing and reporting results.

Literature research was done initially by using electronic databases including Science Direct, ERIC, Wiley Online Library, and Google Scholar. And to be able to do research, the following set of keywords were identified: "education," "creativity, "technology," "computer," "technology", "collaboration," and "collaborative." Then, some other keywords were iteratively developed after examining the titles, abstracts and keywords of studies. Thus, the following keywords were also included in the search process: "digital", "cloud-based", "web-based", "simulation"," "mobile", and "Wiki". Finally, the following search string was created to cover the variables proposed in the research questions (education, collaboration, creativity, and technology). Then, in line with Webster and Watson's (2002) guidelines for conducting literature search and paper selection, which suggest that some leading journals need to be examined manually to ensure reliability, the following two leading journals were examined manually; Thinking Skills and Creativity Journal and Computers and Education. The steps of search and inclusion of studies can be summarized as follows in Figure 1. 


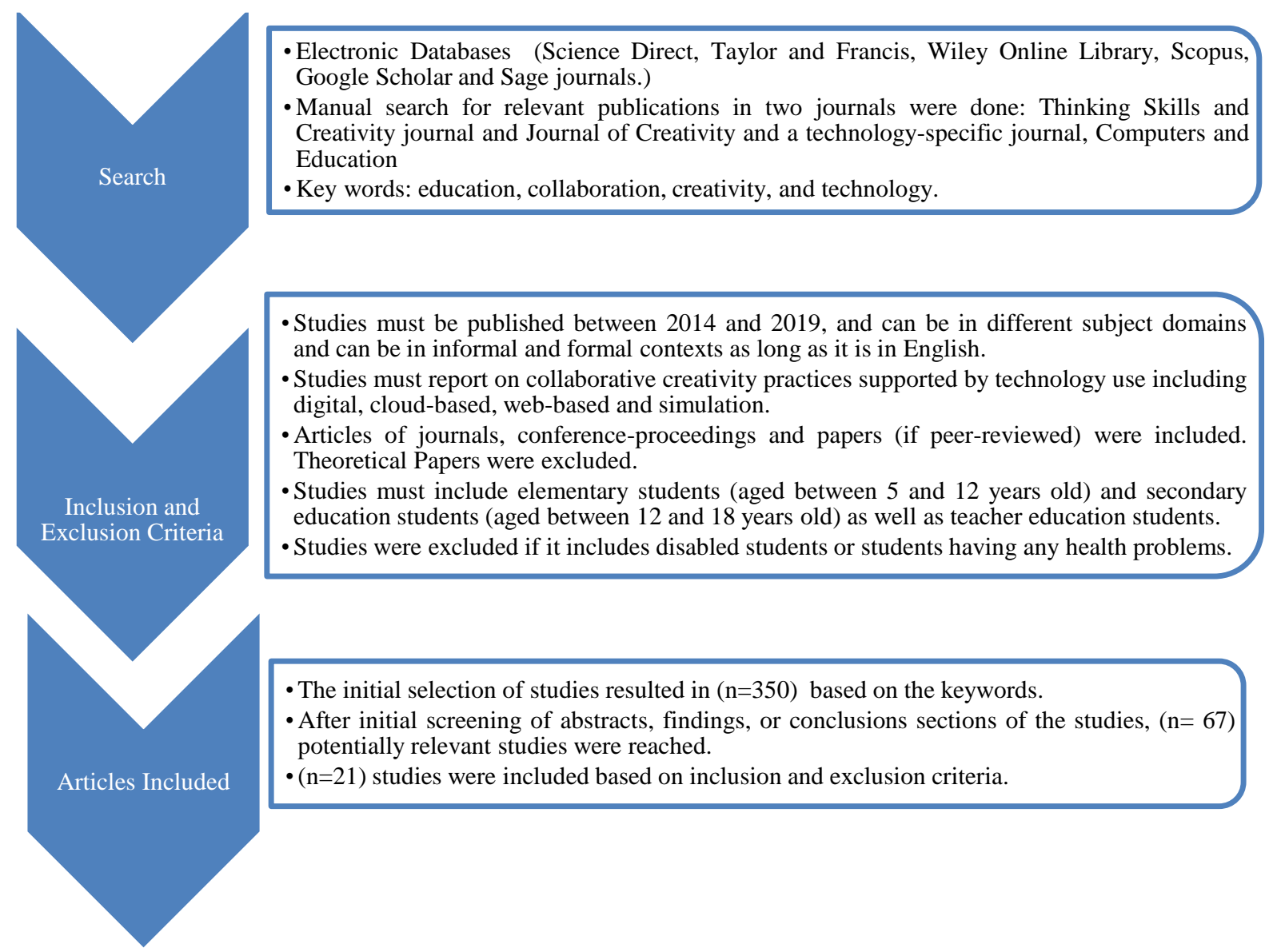

Figure 1. The steps of search and inclusion of studies

As Figure 1 shows above, the initial selection of studies resulted in 350 studies only based on keywords. Data were obtained from the abstract, findings, and conclusion sections of the studies. The initial screening resulted in a database of 67 potentially relevant studies, all between the years 2014 and 2019. These studies were then subjected to further screening based on aforementioned inclusion/exclusion criteria. Forty-six of these studies were excluded from the review since they were not found eligible owing to several reasons such as date $(n=5)$ inappropriate educational level or age group $(n=17)$ or unspecified age $(n=1)$ in one case. Apart from these reasons, some of these studies were excluded mainly because they were focusing on affordances of tech-tools without referring descriptions of practice and their outcomes on students' creativity $(n=10)$ and because they were theoretical papers, book chapters, or reviews $(n=11)$. Of these studies, in one study, there was no mention of a digital tool $(n=1)$, and one other study ( $n=1)$ was only available in Spanish. As a result of this process, only 21 studies were found suitable for the present review.

For data analysis, since qualitative findings of the studies aimed to be analysed systematically, a narrative synthetic approach, which is an approach to the systematic review, was used to categorize, analyse and synthesise the data according to themes developed (Davis et al., 2009). A narrative synthetic approach can be defined as a descriptive written summary of included studies and their findings, and it was mainly preferred when the aim is to summarize the data using words rather than statistically calculate the pooled effect of the findings (Petticrew and Roberts, 2006). The data obtained from the studies were stored in evidence tables, thereby supporting objectivity.

\section{FINDINGS}

The systematic review and analysis have been administered with 21 studies (See Appendix A). In the appendix, the list of the reviewed studies can be found. The analysis of aforementioned studies revealed important insights with regard to conditions and resources for collaborative creativity. The findings are presented under three headings in parallel with the research questions: pedagogical affordances of tech-tools, teachers and students' roles, and specified pedagogical approach/ instruments. Summary of the reviewed studies and overview of the core data extracted from the selected studies aiming to give an answer to the proposed research questions.

\section{Pedagogical applications and affordances of tech-tools (RQ1)}

Table 1 presents information about the forms of technology used in in the reviews based on educational levels. Out of 21 studies, 13 of these were done in secondary education, but one of these studies consisted of both secondary education and elementary education students as study groups (Atwood- Blaine, 2019), and therefore; in counts presented below, the total calculation regarding 
the use of the technological forms in secondary education were $(n=13) .(n=5)$ of these were used in teacher education level, and the rest of these studies $(n=4)$ were done in elementary education level.

Table 1: The forms of technology used in in the reviews based on educational levels

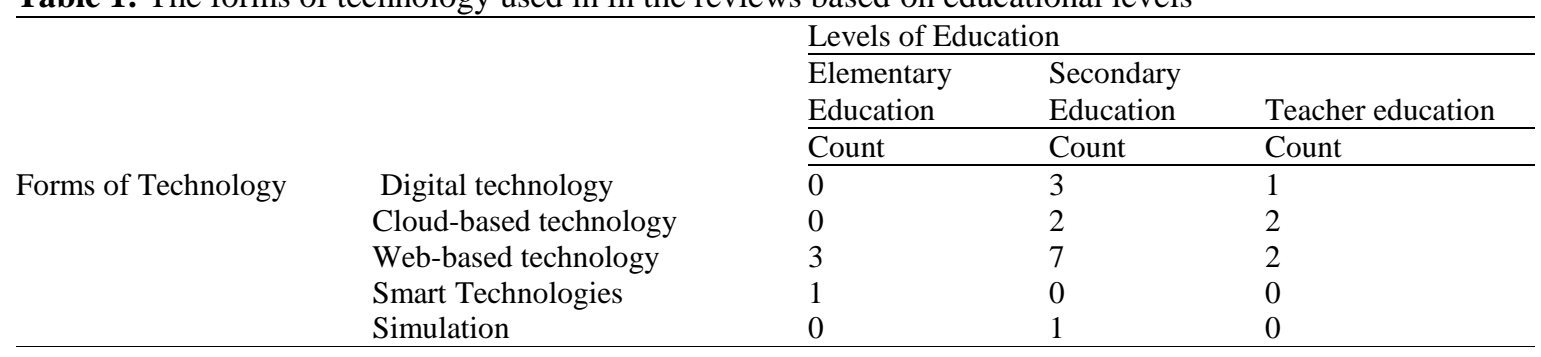

As seen from the table 1, it was seen that web-based technologies or applications constituted the majority $(n=12)$ in the educational levels presented below. The second most used forms of technologies were cloud-based technology (n=4) and digital technology $(n=4)$. Smart technology and simulation were each used once $(n=1$ and $n=1$, respectively). With regard to features of the technologies to promote and orchestrate collaborative creativity, seven forms of technology identified in the studies are presented below.

\section{Web-based Technology}

Web-based technologies were the most widely used technology in the selected studies due to its affordances. The main affordance of web-based technologies is that they include network applications accessible over the Internet. Aside from this, all platforms have properties enabling collaborative creativity. In the selected studies, web-based applications include multimedia, socialmedia, mobile technologies, google docs, wiki platforms, Orbis Dictus platform, Storyboard, Poetry Machine, Docu Viz and Author Viz. In the study conducted by Lin, Chang, Hou, and Wu (2016), it was seen that google docs provided with feasible social learning platform by enabling real-time co-editing, collaborative concept-mapping, interactive communication, revision history, and provided flexible student- driven planning rather than discrete writing process of teacher-driven planning, drafting, redrafting etc.), and due to these affordances, it was found to be more effective platform than paper-pencil method. In the same study, Docu-viz and author-viz tools were also seen to encourage students to monitor each other's' contributions and progress, for instance, whether they do balanced revision and or do group reflection. Orbis-Dictus, another platform used in the study of Poce, Agrusti, and Re (2017) also yielded important benefits like supporting the didactic path by providing all the necessary tools, aside from providing the students with feasible and dynamic environment. In the study of Pifarré et al. (2014), Wiki platform, similar to Google docs platform, was also seen to provide the students with important functions, such as; editing, history, and plus that, different from google docs, it also had a discussion page where the students had the chance to discuss together which in turn fostered group reflection. Multimedia tools, which were used in the Feriansyah (2018), also had an important contribution to students' digital photography task by supplying them with visuals with different effects and transitions, and Story board also enabled students to include or insert photos, description of the photos, and story narration. The use of Poetry machine as web-based application in the study of Kantosalo and Riihialo (2019) also enabled editing, changing words, and creating a poem in collaboration. Mobile Technologies were used only in two of the selected studies. Regarding mobile technology use, and its affordances, Kim, Suh and Song (2015) discussed that mobile phones enabled instant communication and access to information, and its major contribution to collaborative creation was to offer computational tools for learning (e.g. semantic mapping, 3D graphing, stimulating scientific phenomena etc.) Atwood-Blaine (2019) used situated mobile games allowing for creating text, using audio, and taking video notes while also connecting with other players. Atwood- Blaine (2019), apart from using mobile phones, used Glogster, a web-based application, which provided the students with a template for creating electronic posters in collaboration. Lastly, Social Media Technologies were used in Kivunja (2015) where they helped students to share, co-create content, discuss learning and assessment activities, and modify content generated by their peers.

\section{Cloud- Based Technology}

In the selected studies, after web-based technology, cloud-based technologies were the second most used because it can also offer real-time "visual" collaboration just like web-based technologies. In the selected studies, cloud-based technologies consist of caccoo.com, sketcheboard.com, GeoGebra and Edmodo. In the study of Pifarre (2019), it was seen cloud-based technologies (caccoo.com and sketcheboard.com) offered a wide array of collaborative creative practices for its users thanks to their various affordances: 1) accessing others ideas, 2) connecting through cloud-based technology 3) seeing others' ideas simultaneously, 4) making immediate responsiveness to others' ideas and contributions, 5) manipulating shared artefacts, 6) making multimodal representation of ideas, 7) having tangible information, 8.modifying shared artefact), 9) saving information, and 10) reusing saved information. Granberg \& Olsson (2015) conducted a study that employed dynamic software program, GeoGebra, to understand how it fosters students' creative reasoning and collaboration during mathematical problem solving, and it was seen that GeoGebra supplied students with feedback that both verifies and falsifies ideas and hypothesis of them, and also enabled them to try out multiple ideas during (math) problem solving. In the study of Xiang (2016), Edmodo was used by teacher to create a virtual classroom environment for collaborative creative writing project, and it was also used to post rules to the students while the students collaborate and get organized for writing. Besides, Limbua and Markauskaite (2015) preferred to use Cloud-base technology for online collaborative writing practice and the platform helped students to divide work between themselves just like Edmodo platform, 
and like all the other platforms, it enabled them to share ideas and insights, thereby promoting a deeper understanding of what they are doing, in this case, creative writing.

\section{Digital technology}

Digital technology was the third most used technology in the selected studies. In the study of Schmoelz (2018), three digital writing tools were used, and their affordances were explained as follows: a) Iconoscope helped students to develop ideas for the theme by drawing shapes and colours, b) 4Scribes served as collaborative story-writing tool, and c) Creative Stories serve as story-writing tool. Digital Storytelling (DST) Platform (www.meschola.it) was used in the study of Rubino, Barberis and Malnati (2018), and this platform's major affordance was to visualize data with a graph, which helped teachers to give instant feedback to students about their within-group behaviours and interactions. Daskolia, Makri and Kynigos (2014) also preferred to use Digital Storytelling (DST) Platform and they identified three other important features of DST allowing collaborative creativity: a) learning personally meaningful ways b) moving from inquiry to playful activity c) fostering imaginative expression and bricolage. Only in the study conducted by Mudaly, Pithouse-Morgan, Laren, Singh and Mitchell (2015) there was no reference to affordances of digital technology.

\section{Simulation and Smart Technologies}

Simulation and smart technologies were used only once in the selected studies. Out of 21 studies, only Astutik and Prahani's (2018) study employed simulation and discussed features promoting social creativity as follows: 1) visualizations that aid students' understanding, 2) allowing manipulations, and 3) leverage direct student interaction. Apart from this, its main affordance is that it can be used easily in informal educational contexts. In Mercer, Hennessy and Warwick' (2017) study, a smart technology form: Interactive Whiteboard (IWB) was used and its affordances were discussed as follows: 1) enabling co-constructed artefacts to be created which can be saved, modified or reused at a later time. These created artefacts were also found to render learning histories and trajectories more visible, which can help to trace and chart the cumulative progress of class discussions over time.

\section{Pedagogical approaches or conditions (i.e. teacher(s) and student(s)' role) (RQ2)}

RQ2 was answered by referring to a) roles of teacher(s) and student(s), and b) pedagogical approach if specified.

\section{a) Findings with regard to teachers and students' roles to promote collaborative creativity}

Aside from the pedagogical affordances of technologies, another dimension that promotes effective collaborative creativity practices is teachers and students' roles. In most of the selected studies, the majority of teachers preferred giving planned guidance ( $\mathrm{n}=14$ ), two other roles were used by teachers very often: promoting dialogue between students during the process of creation ( $\mathrm{n}=4$ ) and orchestrating collaborative creativity flow of students $(n=4)$. Regarding teachers' and students' roles, the following roles were found based on the reviews.

\section{1) Teachers' role: Giving planned guidance:}

Teachers give planned guidance, scaffold or actively support student's collaborative creativity in the process of creation. Teachers' have a larger role at the beginning, then teachers become facilitators and finally, students take ownership. As a first step, teachers inform students about the steps to follow and provide them with resources or tools that can support and ensure their joint endeavour: joint engagement and equal contribution through assigned roles. Secondly, teachers watch, guide and assist the ones in need of help with clear explanations and demonstrations (i.e., setting rules, answering questions). And, during this stage, although there is a supported practice, there is also student-student interaction (talking, discussing and creating moments) and students take ownership of what they are doing together. At the end, teachers give feedback and assess the creative output. (e.g., Schmoelz, 2018; Kantosalo \& Riihiaho, 2019; Feriansyah, 2018; Rubino et al., 2018; Daskolia et al., 2014; Poce et al., 2017; Kim et al., 2015; Mudaly et al., 2015; Astutik \& Prahani, 2018; Atwood-Blaine, 2019; Ridwan, Rahmawati, and Hadi Nugrahaningsih, 2017; Kivunja, 2015; Xiang, 2016 and Lin, Y.-T. 2016).

\section{Students' roles/ activities: Following planned guidance and performing assigned roles, actions and activities}

In the study conducted by Feriansyah (2018), students were assigned different roles to accomplish the task of digital photography and collaborative writing: 1) project manager, 2) language editor, 3) photo browser, 4) digital operator and 5) story writer. Likewise, Krishnan, Yim, Wolters and Cusimano (2019) also reported about the roles distributed among students during online synchronous collaborative writing: 1) time keeper, 2) goal monitor and 3) facilitator. In Kim et al., 2015, it was seen that each of the students had an explicit role in the design of a new product through roles assigned to them that can be switched, or combined such as documenters, chief engineers, experimenters and team leaders, thereby; keeping power relationship in students' social relationship under control. Besides, in the study of Rubino et al. (2018), students were informed about what they should do to manage creative flow: posting, liking, commenting and suggesting.

In the study of Astutik and Prahani (2018), students were told explicitly what actions they should perform even if they are assigned specific roles, and they performed the following acts by using PhET simulation when they were carrying out a scientific experimentation: 1) students identify problem 2) students explore creative ideas, 3) students collaborate to create, and 4) students 
elaborate on creative ideas. Likewise, in the study of Xiang (2016), the students performed OSGW ( Online Group Story Writing through Edmodo by writing together, but the instructor prescribed them to follow this routine: one person begins a story and a second person reads and continues and a third follows and so on and so forth until everyone has his/her turn.

In the rest of the studies, teachers or researchers just gave students the activities without assigning them any roles (e.g. Schmoelz, 2018; Kantosalo and Riihiaho, 2019; Daskolia et al, 2014; Poce et al., 2017; Kim et al., 2015; Mudaly et al., 2015; Atwood- Blaine, 2019; Ridwan et al., 2017; Kivunja, 2015; Lin, Y.-T. 2016).

\section{2) Teachers' role: Promoting dialogue between students during the process of creation:}

Teachers encourage students to talk about their joint creation process by showing them ways, strategies and language that can be used to think, discuss and create together. In other words, teachers' role is to construct a dialogic ethos, model dialogic practices and encourage student agency e.g., Mudaly et al., 2015; Rubino et al., 2018; Mercer et al., 2017). In Pifarré, Laura and Alex (2014), Students were asked to find a novel solution for a science problem, and to that end, they were taught to improve their discussions in the wiki by using sentence openers as a scaffold to enrich and diverse students' contributions in the wiki. Besides, students were taught about five kinds of openers: 1) to give information (e.g., in my opinion); 2) to learn someone else's point of view by asking questions (e.g. What do you think about; could you give an example); 3) to express disagreement (e.g., I do not agree with; because); 4) to express agreement (e.g., I agree with; because); 5) to give reasons and summarize the discussions (e.g., to synthesize, and thus, students learned some strategies regarding promoting and enriching group dialogue.

\section{Students' roles/ activities: Being in a constant dialogue between each other and performing communicative strategies}

Here, students were informed about communicative strategies (i.e. asking questions, explaining reasons, giving justifications, examples, suggestions and building on one another's ideas etc.). Additionally, students were expected to use these communicative strategies (e.g., Mudaly et al., 2015; Rubino et al., 2018; Mercer et al., 2017). In similar vein, in the study of Pifarre (2019), students were expected to brainstorm and examine pros and cons of ideas etc. as a communicative strategy. In Pifarre et al. (2014), apart from searching about the topic and undertaking a web-based inquiry activity by working in pairs, students also employed communicative strategies exemplified by the instructor: discussing pros and cons of construction of a heating plant next to their city and putting forward arguments in favour or against the construction a heating plant next to their city.

\section{3) Teachers' role: Orchestrating collaborative creativity flow of students:}

Teachers designed different learning phases and tasks with tangible goals to foster groups' creativity flow. Generally, students are guided to inquire and solve problems. Here we have guiding without feeling guided. That is, there is an implicit scaffolding of students. Together with this, the technology is used as tutor by giving feedback orchestrating students' collaborative practices (e.g., Kim et al., 2015; Hemling, Crooks, Oliver, Brenner, Gilbertson, Lisensky and Weibel., 2014 Granberg and Olsson .,2015; Pifarre , 2019).

\section{Students' role/ activities: Performing hands-on roles when doings tasks with tangible goals to foster collaborative creativity flow}

In Hemling et al. (2014), students had explicit hands-on roles in construction of microfluidic device. Similarly, in Kim et al., (2015), students tried to solve everyday science problem: forces and energy. In Granberg and Olsson (2015), the task was mathematical problem and students were expected to use their creative reasoning. In the study of Pifarre (2019), students' role was more about supporting dialogue between each other, and therefore it was not included in this category, but instead included in the category where the students' role is to perform communicative strategies to remain in constant dialogue.

\section{b) Findings with regard to Pedagogical approach/instruments employed to promote collaborative creativity practices in the selected studies}

All of these technological features and their pedagogical affordances would be meaningless and ineffective if teachers use the technology without proper pedagogy. Therefore, pedagogy has of paramount importance. In most of the selected studies, the researchers followed certain theoretical backgrounds or they designed pedagogical principles to reach the aim of their studies.

Except for Kantosalo and Riihiaho (2019), Xiang (2016), and Rubino et al., (2018), all the studies specified either their pedagogical approach or their pedagogical notes or principles to reach their aim of promoting collaborative creativity.

Pifarre (2019) summarized how collaborative creativity fostered with the following five principles: 1) teachers should promote middle-c creativity by involving students in solving a challenge related with the school community, 2) teachers should design phases and subtasks with tangible creative sub-goals, 3) teachers should include activities for "thinking together" (i.e. by asking other students to explain the statements of others, by asking students whether they agree or disagree on the statement provided by someone else, by encouraging students to give reasons/justifications for their views and to provide counter-arguments). 4) students should agree on two different ideas and perspectives across time, and 5) students should experience multimodal ways of interaction (faceto-face and computer) and multilevel (whole class and small group discussion) dialogic interaction. In Pifarre (2019), Middle-c creativity was chosen as one of the principles, and in this study, it was defined as creativity emerged through active participation of peer-group communities to solve a task or a social challenge. Likewise, Pifarré et al. (2014) emphasized four fundamental learning to learn together skills, which include the following principles: 1) mutual engagement, 2) distributed Leadership, 3) peer assessment, 
and 4) group leadership. Different from other studies, Schmoelz (2018) emphasized shared enjoyment and immersion in the absence of conscious awareness of thought and control. Krishnan et al. (2019) also argued in a pedagogical principles aiming for collaborative creativity: 1) task considerations, 2) teaching considerations, and 3) grouping considerations.

Most of the studies adopted student-directed pedagogy that avoids top-down approach and emphasizes social-construction of knowledge by using different theoretical underpinnings. Vygotsky (1978) social constructivist theory, where students should be given realistic tasks to solve and then given sufficient help to solve these tasks were used in some studies (e.g. Feriansyah 2018; Astutik and Prahani 2018; Lin, 2016). The idea is to scaffold students gradually so that students learn to gain knowledge or do something themselves until they no longer need someone's' assistance. Besides, Kivunja (2015) adopted Connectivist theory, which argues for social construction of knowledge through digital tools. Daskolia et al. (2014) employed constructivism that emphasizes learners' creative performance, expressed by active exploration, construction and modification of digital artefacts. Atwood-Blaine (2019) adopted situated learning theory, which emphasizes three main tenets: authentic context, constructivism and social interaction. Mudaly et al. (2015) adopted a humanistic perspective to teach science education which is underpinned by the theory of critical pedagogy because the aim was to avoid a top-down approach and teach science for social responsibility. Both Hemling et al. (2014) and Kim et al. (2015) employed inquiry-based pedagogical approach where teachers are seen as fellow inquirers asking challenging questions to understand scientific phenomena. Ridwan et al. (2017) adopted the STEAM approach in Project-based learning where students learn by doing with hands-on activities.

Poce et al. (2017) and Granberg and Olsson (2015) were different from the rest of the authors in terms of their pedagogical approach because they both adopted the didactic approach in which students are asked to carry out the target activities under constant surveillance and control by the teacher. In the case of Poce et al. (2017), technology also served as the tutor, aside from the teacher. However, the didactic approach implemented in this study did not undermine social interaction between students.

\section{Problems and possible solutions (RQ3)}

This part provides a discussion of teacher-related, student-related and tech-related problems and solutions in the selected studies. The types of problems observed in the studies are presented in Figure 2.

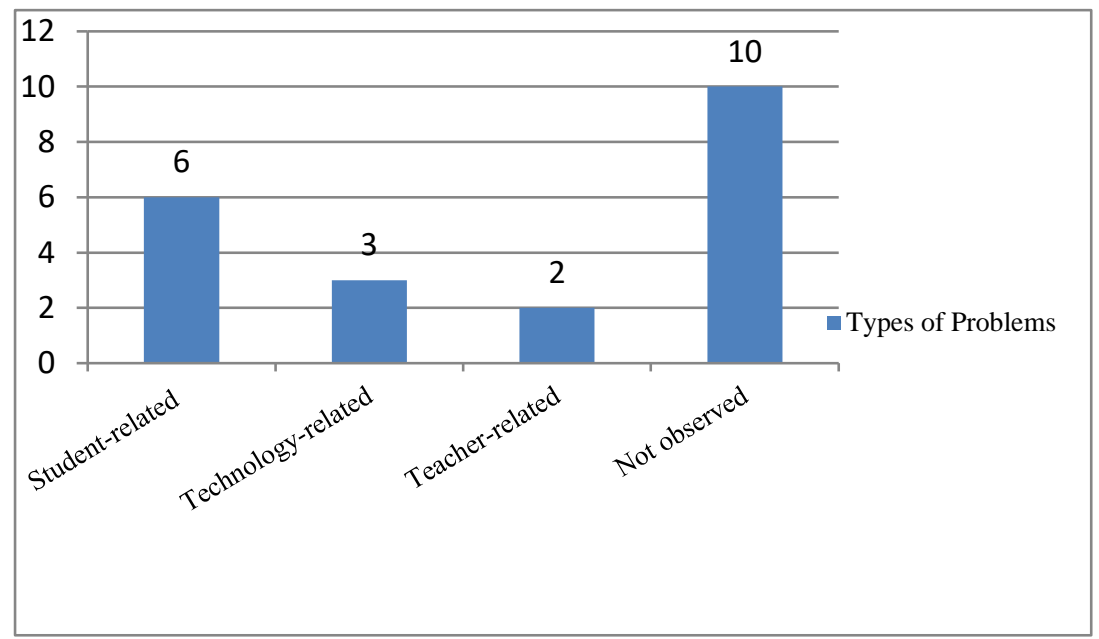

Figure 2. Types of problems observed in the selected studies

As shown in figure 2, types of problems observed in the selected studies were categorized as student-related, technology-related and tech-related. In some of the studies, there was no mention of any problems (e.g., Hemling et al, 2014; Mudaly et al., 2015; Lin, Y.-T. 2016; Astutik and Prahani, 2018; Atwood-Blaine, 2019; Ridwan et al., 2017; Schmoelz, 2018; Limbu and Markauskaite, 2015; Poce et al., 2017; Mercer et al., 2017).

\section{Student-related problems}

Student-related problems were the one encountered most in the selected studies. In the study of Granberg and Olsson (2015), there were some students engaged in shallow discussions (i.e., out of topic, or irrelevant discussions) because some of them did not go with group rules. As a solution, the teacher monitored the student talks when it stagnates and becomes shallow, thereby regulating the quality of group discussions. Xiang (2016), observed a problem in the plot design of story-writing. In the plot design, each and every one of the students took turns at the beginning, middle, and ending. For instance, one of the students do the beginning and then leave the other student to continue write the middle, then the one who is responsible of writing the middle part of the plot leave the conclusion part to another student. The problem is that taking turns led some of the students feel anxious regarding the quality of plot since they need to trust each other's writing. Though this stood as an important handicap ahead of the students, students learned to be considerate and careful in their plot design by leaving their group members as many imaginations as possible to continue the story. Students also had a language problem because students were Chinese and yet they were expected to write in English, but the teacher solved this problem by guiding them to use an online dictionary and word-processor, to get help from friends and from the Internet. Krishnan et al. (2019) also witnessed group interaction problem in writing process, but the teacher overcame 
this by encouraging reflection on Group Writing. Pifarré et al. (2014) likewise argued not all students showed learn together skills. Daskolia et al. (2014) also observed some incidents of misunderstandings and communication, again referring to group dynamics problem, but disagreements and tension within the group were used as an advantage to create collaboration. Kim et al. (2015) observed a different problem: when using mobile technology, it was seen that there was a lot peeking, copying, imitating, replicating, and reusing ideas within the entire class. However, this was not seen as something negative again because students learn from each other, think together and act in collaboration.

\section{Technology-related problems}

Technology-related problems were the second most experienced problems. Pifarre (2019) discussed about technology-related problems such as difficulties to enter the shared-space, non-visualization of others' contributions in the shared-space; unfamiliarity with specific software options or lack of internet connection. Nevertheless, it was noted that these problems were addressed with solutions provided by students a) students assisted other students having technological problems and offering help to solve his/her problems by giving prompt and easy-to-understand explanations on how to solve those technological issues; c) students provided explanations by modelling how to solve the problem or by showing these in his/her computer screen and d) students learn and work together to take maximum advantage of software's affordances. Kantosalo and Riihiaho (2019) also discussed about technologyrelated problems occurred during poetry writing. In this study, the problem was mainly caused by the students' use of several pointers on one computer which led to competition and conflicts among students. Feriansyah (2018) also discussed some of the technical problems encountered during story-writing, but again these problems were solved by students' help to one another (e.g. discussing with the group how to adjust the story duration and asking for group members' opinion how to record the voice-over).

\section{Teacher-related problems}

A majority of the studies referred to student-related and tech-related problems encountered in the activities except for two studies where teacher-related problems are discussed. In these studies, teacher-related problems are related to those discussed in the teacher roles section of this paper. Mainly, teacher-related problems are caused by teachers' management style, which causes loosened discipline and some group interaction problems. This loosened discipline is also the consequence of not giving planned guidance (e.g. not explaining and assigning roles), and orchestrating collaborative creativity flow of students (e.g. group interaction and communication problems). In the study conducted by Rubino et al., (2018), the problem of unbalanced interaction and out of topic conversations was caused by teachers' style of management. In the study, two different teacher roles were compared in terms of effectiveness of management. While Teacher A gave greater degree of freedom both in terms of the time available to complete the tasks and of the contents to be developed, Teacher B provided the students with more defined mission. In the first case, Teacher A's style triggered loosened discipline and some group interaction problems, but meanwhile this gave them a greater degree of freedom. On the other hand, Teacher B's style produced more balanced group interaction and less out of topic conversations. The results of this study suggested that regardless of teachers' (teacher A and teacher B) different roles, collaboration and creativity emerged, but it was seen teacher B' management style produced more focussed behaviours than teacher A. Kivunja (2015) noted another issue that affect teachers. According to findings of the study, collaborative creativity practice put extra workload on the teachers' shoulder. However, this was appreciated by the students because they were aware of the extra effort their teacher put to teach them something new in a novel way. Also, the teacher feels the burden, but s/he was aware that the students would become more interested and engaged which in return made his/her job easier. That is to say, the burden of implementing something novel was perceived as positive thing both by teachers and students.

Table 2. Teach-related problems and Teacher A and Teacher B comparison in terms of effectiveness of management style

Problem 1: Teachers' management style: Teachers A versus. Teacher B (Rubino et al., 2018)

Teacher A: do not give planned guidance: (e.g. not explaining and assigning roles) and do not orchestrate collaborative

creativity flow of students (e.g. unbalanced interaction and out of topic conversations)

* triggered loosened discipline

*created group interaction problems

Teacher B: Give more defined mission assigned to the students.

*more balanced group interaction and less out-of topic conversations

* more focussed behaviours

Problem 2: Extra Workload: Perception of a teacher versus. Students (Kivunja, 2015)

Teacher's view: The teacher feels the burden, but s/he is aware that the students would become more interested and engaged. Student's view: Extra workload is appreciated by the students because they are aware of the extra effort their teacher put to teach them something new in a novel way.

\section{DISCUSSION OF THE FINDINGS AND CONCLUSION}

This systematic review informed teachers and scholars regarding necessary conditions to foster technology-enabled collaborative creativity practices. Figure 3 presents some important steps that need to be followed by an instructor to foster collaborative creativity. 

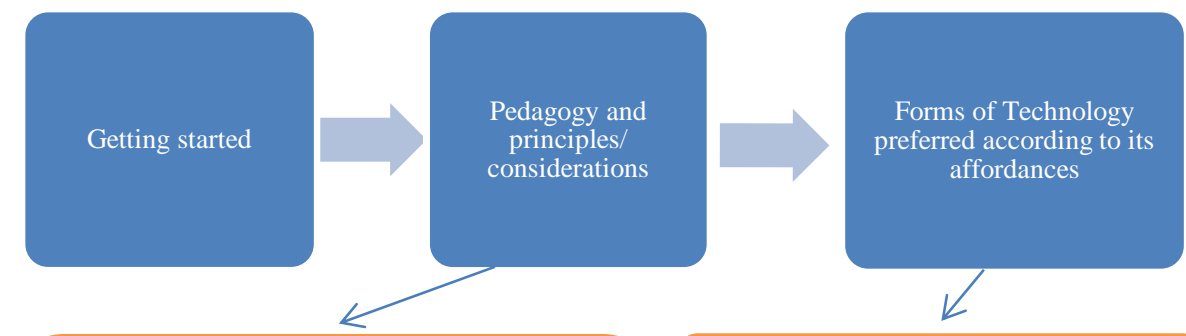

Pedagogy: Inquiry-based, Humanistic, didactic, Constructivist, Connectivist, Social constructivist, STEAM.

Web-based, cloud-based, Digital, smart tech, and simulation.

Principles and considerations: Middle-c creativity, learning to learn together skills, task considerations, teaching considerations, grouping considerations.

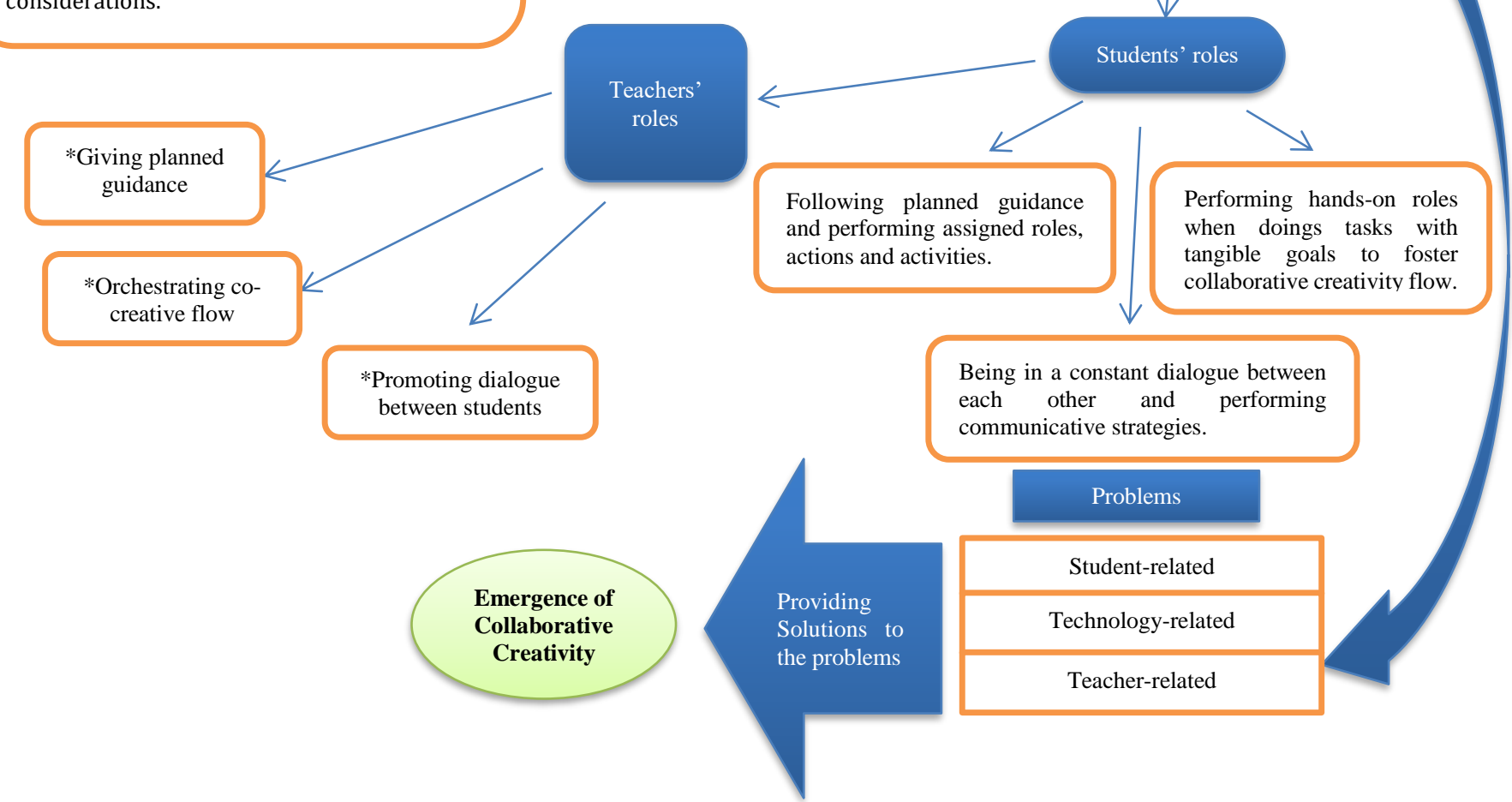

Figure 3. The steps and process followed in the selected studies for the emergence of collaborative creativity.

As shown in figure 3, the steps and process followed in the selected studies for the emergence of collaborative creativity include first determination of the pedagogy and principles, which is later followed by determination of form of technology according to its affordances. Here, this decision was taken according to match between task and form of technology. After deciding these two initial steps, there is another decision-making process ahead of teachers, which include: to decide teachers' role and students' role and to provide solutions to the three types of problems (student-related, technology-related and teacher-related) that they may encounter. After going through all these processes successfully, it is possible to foster collaborative creativity.

The findings indicated that majority of the studies employed student-directed pedagogy and learning theories that underpin socialconstructivism. These are: 1) Inquiry-based pedagogical approach, 2) Humanistic perspective supported by the critical pedagogy, 3) Didactic Approach, 4) Constructivism, and 5) Connectivist theory and 6) STEAM approach. Aside from these, studies also highlighted some important pedagogical principles and conducted their studies based on this premises. Some of the implications of these principles are important to discuss for future avenues. First, students should be directed to be creative by solving a real challenge in a social world, and teachers should design phases and goals as clear as possible (Pifarre, 2019). Moreover, as discussed in Pifarré et al., 2014, students need to learn how to learn together and they need to be equipped with these skills. That is, they need to learn to establish mutual engagement, distribute leadership among themselves, learn to do peer-assessment, and also pick up the right person for group leadership. To be more precise, the task, the teaching approach and the group dynamics should be planned in advance, but at the same time, there should not be enforced control over the students which would inhibit their actions and creativity. In line with Csikszentmihalyi (1997), the selected studies showed that precise goals should be set by instructors, yet meanwhile the absence of awareness and conscious control are essential to maintain co-creative flow of students.

As discussed in the studies, three major roles were identified for teachers: 1) giving planned guidance, 2) promoting dialogue between students during the process of creation and 3) orchestrating collaborative creativity flow of students. None of the identified roles of teachers portray teachers as a complete bystander to students' collaborative creation process. Instead, teachers are there to 
mentor, monitor and facilitate the process in three different ways. The studies also highlighted that the conception of teacher as a direct source of information can be avoided and learning and doing process can be more student-centred if teachers conduct a need analysis (Herbert, 2007; Lim \& Morris, 2009). Instructors need to know about group dynamics, students' level of openness to dialogue and collaboration, students' knowledge of communicative strategies and ICT, and how to assign roles to students based on student characteristics and so forth. For this reason, this review gives an important tip to teachers and educators: if they can carry out a need analysis, a facilitating deep learning approach can be used more effectively (Floyd, K. S., Harrington, S. J., \& Santiago, J.; 2009; Jang, 2008; Rovai, 2007).

Students' roles were also found to be in parallel with teachers' roles: 1) following planned guidance and performing assigned roles, actions and activities, 2) being in a constant dialogue among each other and performing communicative strategies, 3) performing hands-on roles while doings tasks with tangible goals to foster collaborative creativity flow. This shows that it is important to create collaboration of a teacher and student to ensure collaborative creativity from outside and inside. Thus, it is possible to keep students under control while offering students a degree of freedom that fosters co-creative flow.

Regarding the forms of technology used, web-based technologies were found as the most widely used form of technology. Then, the list was followed by cloud-based technology as the second most used and digital technology as the third most used technologies. The rest of the technologies, simulation and smart technologies, were used only once. Apart from its features, the major reason why web-based preferred widely is because web-based technology devices such as mobile phones, social media, computer and so forth. can be used by mainstream. The cloud-based technology came out as the second most used technology because just like web-based technology, it can offer real time communication, and additionally, it can offer "visual" communication and can be used offline. Due to these features, cloud-based technology is far more collaboration-based compared to web-based technology, but despite this, web-based technology has nevertheless the upper hand in the studies. This may be attributed to the fact that web-based technology has longer history and it is cheaper compared to cloud-based technology.

Three main problems were identified in the selected studies: teacher-related, student-related and tech-related problems. And among these, "student-related" problems came out as the most commonly encountered problem. This was followed by technology-related problems and then by teacher-related problems. Majority of the student-related problems were about unbalanced contribution, shallow (unproductive) discussions, and experiences of disagreements and tension among students. As for technology-related problems, students' unfamiliarity with the softwares and technological tools were listed as one of the major shortcomings experienced by the students. In addition to this, the features of technological tools sometimes led to competition and conflicts among students. When it comes to teacher-related problems, teachers' management styles stand out as the main reason. Though different types of problems identified in the studies, it was indicated that these problems could be tackled through student-student and teacherstudent cooperation and communication. Therefore, this study can inform teachers/educators that obstacles and challenges should not fear them because students can find ways to handle them with ease as long as they communicate among each other, and as long as teachers assist them by guiding them to solutions. Therefore, in the selected studies, the majority of the problems could be solved and even disadvantages could be turned into advantages when the collaborative spirit was maintained. Students could solve the problems in three ways: 1) by solving the problems coming together, 2) by being considerate towards their team members and 3) by valuing their teachers' effort. Therefore, it would not be wrong to say that, in the papers selected for this review, problems were not perceived as obstacles to collaborative creativity both by the students and the teachers. Instead, they were considered as a means to boost collaboration and creativity.

There are some limitations on the findings of the systematic review however. This systematic review was limited to peer-reviewed articles written between 2014 and 2019. The fact that only 21 publications have been analysed may have limited the impact of our implications and recommendations. Apart from this, the selected key words chosen might not include some other possible combinations of keywords, thereby leading up to another limitation. Lastly, major limitation may have caused because of discussing different forms of technology, educational contexts and subject domains which require heterogeneous screening of studies, but in order to control these shortcomings, the key words were kept as much rich and inclusive as possible. Despite these limitations discussed above, the findings of this study have several important implications for future research:

I. Much of the studies conducted are qualitative, and therefore, future studies should design a larger-scale empirical study and should design mixed method approach to provide different insights.

II. Even though there have been several studies conducted using different technological tools, future studies should further investigate effective ways to establish a dialogic, multimodal and multi-voiced shared-digital space by focusing more on group dynamics, teachers' roles and student roles. Moreover, while implementing collaborative creativity, it is important for students to engage in reflective dialogues to maintain group spirit and interaction. Hence, future studies should further investigate the ways of supporting reflective dialogues that widen and deepen students' understanding of collaborative creativity practices.

III. Apart from these, future studies should be done to investigate further how co-creative flow emerges with implicit knowledge, in other words, without conscious awareness of thought and control.

In addition to implications for future research, the following recommendations for policy and practice have been drawn out based on the findings of this review: 
I. It would be helpful if teachers get training about the ways to promote technology-mediated collaborative creativity of students in educational contexts. To be more precise, even if teachers have enough technological competence, many of them still do not know practical ways to boost collaborative creativity by using technological tools. This is mainly because they may not have knowledge regarding pedagogical affordances of technological tools. Therefore; if training provided to teachers, they can provide better environment to produce collaborative creativity by matching the features of technology with the task considered to be implemented.

II. It would be helpful if students get training on working as a team member and teachers get training on controlling group dynamics. Group dynamic is an important variable to control to ensure collaborative creativity. In this respect, students need to learn what is meant to be a team member whereas teachers need to know what criteria need to be considered before allocating students to groups or peers. As discussed in the selected studies, collaborative creativity cannot emerge in the absence of disagreements and tension, and yet these should not be in the form of fight and competition among students. This fine line between disagreements and fight, and tension and competition need to be set properly, by rendering this training an absolute requirement.

III. It would be helpful if a need analysis can be conducted by teachers before creative collaboration practice. This is absolutely necessary because if an instructor wants to use facilitative deep learning approach in a more effective way, then they need to know about the needs of students. If they meet the need of students, this can give way to more student-centred approach and can foster emergence of co-creative flow with implicit knowledge where there is little to no teacher interference to students' practice except for guiding explanations and demonstrations.

In a nutshell, this paper has reviewed 21 studies on tech-enhanced collaborative creativity practices conducted in the field of education between 2014 and 2019. The review has focused on important issues that are key to foster collaborative creativity, and as a result, it was seen that for the emergence of collaborative creativity, the studies follow similar decision-making process: 1) deciding pedagogy / principles, 2) deciding forms of technology based on its affordances, and after that, 3) deciding teachers' role and students' role, and finally 4) solving problems. These are the key educational variables enabling or inhibiting the emergence of collaborative creativity. In this respect, this review has contributed to the field by identifying the key educational variables, and by showing how these variables have been implemented in the most effective way in the selected studies.

Ethics and Consent: Ethics committee approval is not required as it does not involve clinical researches on humans as well as it does not contain Retrospective studies in accordance with the Law on Protection of Personal Data.

\section{REFERENCES}

Astutik,S., \& Prahani, B. K. (2018). The Practicality and Effectiveness of Collaborative Creativity Learning (CCL) Model by Using PhET Simulation to Increase Students' Scientific Creativity. International Journal of Instruction, 11(4), 409-424.

Atwood-Blaine, D., Rule, A. C., \& Walker, J. (2019). Creative self-efficacy of children aged 9-14 in a science center using a situated Mobile game. Thinking Skills and Creativity, 33, 100580. https://doi.org/10.1016/j.tsc.2019.100580

Beijaard, D., Verloop, N., \& Vermunt, J. (2000). Teachers' perceptions of professional identity: An exploratory study from a personal knowledge perspective. Teaching and Teacher Education, 16(7), 749-764.

Craft, A. (2001). An analysis of research and literature on creativity in education report prepared for QCA. London: QCA

Craft, A. (2012). Childhood in a digital age: creative challenges for educational futures. Lond. Rev. Educ. 10, 173-190. doi: $10.1080 / 14748460.2012 .691282$

Chiu, C.-H., \& Hsiao, H.-F. (2010). Group differences in computer supported collaborative learning: Evidence from patterns of Taiwanese students' online communication. Computers and Education, 54(2), 427-435. https://doi.org/10.1016/j.compedu .2009 .08 .026

Csikszentmihalyi, M. (1997). Creativity: Flow and the psychology of discovery and invention. New York: Harper.

Daemmrich, I. G. Assessing collaborative writing in nontraditional and traditional first-year college writing courses (2010) Teaching English in the Two-Year College, 38(2), 161-175.

Daskolia, M., Makri, K., \& Kynigos, C. (2014). Fostering collaborative creativity in learning about urban sustainability through digital storytelling. In G. Futschek, \& C. Kynigos (Eds.), Constructionism and Creativity: Proceedings of the 'Constructionism 2014' International Conference, Vienna, Austria, 19-23 August (pp. 357-366). Vienna: Österreichische Computer Gesellschaft.

Eteläpelto, A. \& Lahti, J. (2008). The resources and obstacles of creative collaboration in a long-term learning community. Thinking Skills and Creativity, 3, 226-240. doi:10.1016/j.tsc.2008.09.003

Feriansyah,S.(2018).Collaborative narrative writing: A digital photography task in an Indonesian Islamic secondary school: Indonesian Journal of Applied Linguistics. 8 (2), 303-315

Floyd, K. S., Harrington, S. J., \& Santiago, J. (2009). The effect of engagement and perceived course value on deep and surface learning strategies. Informing Science, 12, 181-190.

Frodesen, J., Eyring, J., \& Larsen-Freeman, D. (2007). Grammar dimensions. form, meaning, and use. Boston, MA: Thomson/Heinle.

Glăveanu, V. P. (2008). Thinking outside the box of individualism: creativity in light of a socio-cultural approach (editorial). Europe's J. Psychol. 4. doi: 10.5964/ejop.v4i4.437

Glăveanu, V. P. (2014). Distributed Creativity: Thinking Outside the Box of the Creative Individual. New York, NY: Springer. doi: 10.1007/978-3-319-05434-6 
Granberg, C., \& Olsson, J. (2015). ICT-supported problem solving and collaborative creative reasoning: Exploring linear functions using dynamic mathematics software. The Journal of Mathematical Behavior, 37, 48-62. https://doi.org/10.1016/j.jmathb.2014.11.001

Hemling, M., Crooks, J. A., Oliver, P. M., Brenner, K., Gilbertson, J., Lisensky, G. C., \& Weibel, D. B. (2013). Microfluidic s for High School Chemistry Students. Journal of Chemical Education, 91(1), 112-115. https://doi.org/10.1021/ed4003018

Henriksen, D., Mishra, P., \& Fisser, P. (2016). Infusing creativity and technology in 21 st century education: a systemic view for change. Educ. Technol. Soc., 19, 27-37.

Herbert, M. (2007). Get your retention act together now: 8 pieces of advice. Distance Education Report, 11(9), 3-7.

Huang, H. (2002). Toward constructivism for adult learners in online learning environments. British Journal of Educational Technology, 33(1), 27-37.

Irene R. (2018) Exploring the values of writing collaboratively through a digital storytelling platform: a mixed-methods analysis of users' participation, perspectives and practices, Interactive Learning Environments, 26,7, 882894, DOI: 10.1080/10494820.2017.1419499

Jang, H., Reeve, J., \& Deci, E. L. (2010). Engaging students in learning activities: It is not autonomy support or structure but autonomy support and structure. Journal of Educational Psychology, 102(3), 588-600. doi: Doi 10.1037/A0019682

Johnson, L., Adams Becker, S., Estrada, V., \& Freeman, A. (2014). NMC Horizon Report: 2014 K-12 Edition. Austin, Texas: The New Media Consortium.

Kantosalo, A., \& Riihiaho, S. (2019). Quantifying co-creative writing experiences. Digital Creativity, 30(1), 2338. https://doi.org/10.1080/14626268.2019.1575243

Kim, P, Suh. E., \& Song,D. (2015). Development of a design-based learning curriculum through design-based research for a technology-enabled science classroom. Educational Technology. Research and Development., 63, 575-602. doi: $10.1007 / \mathrm{s} 11423-015-9376-7$

Kirschner, P., Sweller, J., \& Clark, R. (2006). Why minimal guidance during instruction does not work: An analysis of the failure of constructivist, discovery, problem-based, experiential and inquiry-based teaching. Educational Psychologist, 41, 75-86. https://doi.org/10.1207/s15326985ep4102_1

Kivunja, C. (2015). The Efficacy of Social Media Technologies in Academia: A Pedagogical Bliss or Digital Fad?. International Journal of Higher Education., 4(4). https://doi.org/10.5430/ijhe.v4n4p33

Krishnan, J., Yim, S., Wolters, A., \& Cusimano, A. (2019). Supporting Online Synchronous Collaborative Writing in the Secondary Classroom. Journal of Adolescent \& Adult Literacy, 63( 2), 135- 145. https://doi.org/10.1002/jaal.969

Lee, M. R., and Chen, T. T. (2015). Digital creativity: research themes and framework. Comput. Human Behav. 42, 12-19. doi: 10.1016/j.chb.2014.04.001

Levac, D., Colquhoun, H., and O'Brien, K. K. (2010). Scoping studies: advancing the methodology. Implement. Sci. 5:69. doi: $10.1186 / 1748-5908-5-69$

Lim, D. H., \& Morris, M. L. (2009). Learner and instructional factors influencing learning outcomes within a blended learning environment. Educational Technology \& Society, 12(4), 282-293.

Limbu, L., \& Markauskaite, L. (2015). How do learners experience joint writing: University students' conceptions of online collaborative writing tasks and environments. Computers and Education, 82, 393-408.

Lin, Y.-T., Chang, C.-H., Hou, H.-T., \& Wu, K.-C. (2016). Exploring the effects of employing Google Docs in collaborative concept mapping on achievement, concept representation, and attitudes. Interact. Learn. Environ., 24, 1552-1573. doi: $10.1080 / 10494820.2015 .1041398$

Lowenthal, P. N., \& Dunlap, J. (2007). Digitalstories.In P. Shank (Ed.),The online learning idea book:95 proven ways to enhance technology-based and blended learning (pp. 110-111). San Francisco: Pfeiffer.

Mercer, N., Hennessy, S., \& Warwick, P. (2017). Dialogue, thinking together and digital technology in the classroom: some educational implications of a continuing line of inquiry. Int. J. Educ. Res. doi: 10.1016/j.ijer.2017.08.007 Available online at: https://www.sciencedirect.com/science/article/pii/S0883035517303877

Moran, S. (2010). Creativity in school. In K. Littleton, C. Wood, \& J. Kleine-Staarman (Eds.). International handbook of psychology in education (pp. 319-359). Bingley: Emerald.

Mudaly, R., Pithouse-Morgan, K., Laren, L.V., Singh, S., \& Mitchell, C. (2015). Connecting with Pre-Service Teachers' Perspectives on the Use of Digital Technologies and Social Media to Teach Socially Relevant Science. Perspect. Educ., 33, 23-41.

Petticrew M., \& Roberts H. (2006). Systematic Reviews in the Social Sciences: A Practical Guide. Malden, MA: Blackwell Publishing.

Pifarré, M., Laura, M., \& Alex, G. (2014). Collaborative Creativity Process in a WIKI: A study in Secondary Education. Paper presented at the International Conference on Cognition and Exploratory Learning in Digital Age CELDA. 11th, Porto, Portugal, Oct 25-27.

Pifarre, M. (2019). Using interactive technologies to promote a dialogic space for creating collaboratively: A study in secondary education. Thinking Skills and Creativity. https://doi.org/10.1016/j.tsc.2019.01.004

Poce, A., Agrusti, F., \& Re, M. R. (2017). Enhancing higher education students' XXI century skills through co-writing activities in science teaching. J. E-Learn. Knowl. Soc., 13, 51-64.

Ridwan, A., Rahmawati, Y., \& Hadi Nugrahaningsih, T. (2017). STEAM integration in chemistry learning for developing 21st century skills. MIER J. Educ. Stud., 7, 184-194.

Rubino, I., Barberis, C., \& Malnati, G. (2018). Exploring the values of writing collaboratively through a digital storytelling platform: a mixed-methods analysis of users' participation, perspectives and practices. Interactive Learning Env., 26(7), 882-894

Rovai, A. P. (2007). Facilitating online discussions effectively. The Internet and Higher Education, 10(1), 77-88. 
Sawyer, R. K. (2012). Explaining Creativity: The Science of Human Innovation. New York, NY: Oxford University Press.

Schmölz, A. (2018). Enabling co-creativity through digital storytelling in education. Thinking Skills and Creativity. https://doi.org/10.1016/j.tsc.2018.02.002

Vygotsky, L. (1987). The Collected Works of L.S. Vygotsky. New York, NY: Plenum Press.

Webster, J., \& Watson, R. (2002). Analyzing the past to prepare for the future: writing a literature review. Management Information Systems Quarterly, 26, xiii-xxiii

Wheeler S., Waite S. J. \& Bromfield C. (2002). Promoting creative thinking through the use of ICT, Journal of Computer Assisted Learning, 18, 367-378

Xiang, Z. (2016). "Advanced Chinese EFL Learners' Experiences and Perceptions of OGSW - An Online Collaborative Creative Writing Project," 2016 International Conference on Educational Innovation through Technology (EITT), Tainan, pp. 187192

Yim, S., \& Warschauer, M. (2017). Web-based collaborative writing in L2 contexts: Methodological insights from text mining. Language Learning \& Technology, 21(1), 146-165. https:// doi.org/10125/44599

\section{APPENDIX A: Reference List of the Reviewed Articles (N=21)}

1. Pifarre, M. (2019) .Using interactive technologies to promote a dialogic space for creating collaboratively: A study in secondary education. Thinking Skills and Creativity. https://doi.org/10.1016/j.tsc.2019.01.004

2. Schmölz, A. (2018). Enabling co-creativity through digital storytelling in education. Thinking Skills and Creativity. https://doi.org/10.1016/j.tsc.2018.02.002

3. Kantosalo, A., \& Riihiaho, S. (2019). Quantifying co-creative writing experiences. Digital Creativity, 30(1), 2338. https://doi.org/10.1080/14626268.2019.1575243

4. Feriansyah,S.(2018).Collaborative narrative writing: A digital photography task in an Indonesian Islamic secondary school: Indonesian Journal of Applied Linguistics. 8 (2), 303-315

5. Limbu, L., \& Markauskaite, L. (2015). How do learners experience joint writing: University students' conceptions of online collaborative writing tasks and environments. Computers and Education, 82, 393-408.

6. Krishnan, J., Yim, S., Wolters, A., \& Cusimano, A. ( 2019). Supporting Online Synchronous Collaborative Writing in the Secondary Classroom. Journal of Adolescent \& Adult Literacy, 63( 2), 135- 145. https://doi.org/10.1002/jaal.969

7. Rubino, I., Barberis, C., and Malnati, G. (2018). Exploring the values of writing collaboratively through a digital storytelling platform: a mixed-methods analysis of users' participation, perspectives and practices. Interactive Learning Env. 26(7),882-894

8. Pifarré, M., Laura, M., \& Alex, G. (2014). Collaborative Creativity Process in a WIKI: A study in Secondary Education. Paper presented at the International Conference on Cognition and Exploratory Learning in Digital Age CELDA. 11th, Porto, Portugal, Oct 25-27.

9. Daskolia, M., Makri, K., \& Kynigos, C. (2014). Fostering collaborative creativity in learning about urban sustainability through digital storytelling. In G. Futschek, \& C. Kynigos (Eds.), Constructionism and Creativity: Proceedings of the 'Constructionism 2014' International Conference, Vienna, Austria, 19-23 August (pp. 357-366). Vienna: Österreichische Computer Gesellschaft.

10. Poce, A., Agrusti, F., \& Re, M. R. (2017). Enhancing higher education students' XXI century skills through co-writing activities in science teaching. J. E-Learn. Knowl. Soc. 13, 51-64.

11. Mercer, N., Hennessy, S., \& Warwick, P. (2017). Dialogue, thinking together and digital technology in the classroom: some educational implications of a continuing line of inquiry. Int. J. Educ. Res. doi: 10.1016/j.ijer.2017.08.007 Available online at: https://www.sciencedirect.com/science/article/pii/S0883035517303877

12. Lin, Y.-T., Chang, C.-H., Hou, H.-T., and Wu, K.-C. (2016). Exploring the effects of employing Google Docs in collaborative concept mapping on achievement, concept representation, and attitudes. Interact. Learn. Environ. 24, 15521573. doi: 10.1080/10494820.2015.1041398

13. Kim, P, Suh. E.,\& Song,D. (2015). Development of a design-based learning curriculum through design-based research for a technology-enabled science classroom. Educational Technology. Research and Development. 63, 575-602. doi: $10.1007 / \mathrm{s} 11423-015-9376-7$

14. Hemling, M., Crooks, J. A., Oliver, P. M., Brenner, K., Gilbertson, J., Lisensky, G. C., \& Weibel, D. B. (2013). Microfluidics for High School Chemistry Students. Journal of Chemical Education,91(1), 112-115. https://doi.org/10.1021/ed4003018

15. Mudaly, R., Pithouse-Morgan, K., Laren, L.V., Singh, S., \& Mitchell, C. (2015). Connecting with Pre-Service Teachers' Perspectives on the Use of Digital Technologies and Social Media to Teach Socially Relevant Science. Perspect. Educ. 33, 23-41.

16. Granberg, C., \& Olsson, J. (2015). ICT-supported problem solving and collaborative creative reasoning: Exploring linear functions using dynamic mathematics software. The Journal of Mathematical Behavior,37, 48-62. https://doi.org/10.1016/j.jmathb.2014.11.001

17. Astutik,S., \& Prahani, B. K. (2018). The Practicality and Effectiveness of Collaborative Creativity Learning (CCL) Model by Using PhET Simulation to Increase Students' Scientific Creativity. International Journal of Instruction. 11,4.

18. Atwood-Blaine, D., Rule, A. C., \& Walker, J. (2019). Creative self-efficacy of children aged 9-14 in a science center using a situated Mobile game. Thinking Skills and Creativity, 33, 100580. https://doi.org/10.1016/j.tsc.2019.100580 
19. Atwood-Blaine, D., Rule, A. C., \& Walker, J. (2019). Creative self-efficacy of children aged 9-14 in a science center using a situated Mobile game. Thinking Skills and Creativity, 33, 100580. https://doi.org/10.1016/j.tsc.2019.100580

20. Kivunja, C. (2015). The Efficacy of Social Media Technologies in Academia: A Pedagogical Bliss or Digital Fad?. International Journal of Higher Education. 4(4). https://doi.org/10.5430/ijhe.v4n4p33

21. Xiang, Z. (2016). "Advanced Chinese EFL Learners' Experiences and Perceptions of OGSW - An Online Collaborative Creative Writing Project," 2016 International Conference on Educational Innovation through Technology (EITT), Tainan, pp. 187-192 